BMJ Open Sport \& Exercise Medicine

\section{Is competitive body-building pathological? Survey of 984 male strength trainers}

To cite: Steele I, Pope H, Ip EJ, et al. Is competitive body-building pathological? Survey of 984 male strength trainers. BMJ Open Sport \& Exercise Medicine 2020;6:e000708. doi:10.1136/ bmjsem-2019-000708

Accepted 21 April 2020
(C) Author(s) (or their employer(s)) 2020. Re-use permitted under CC BY-NC. No commercial re-use. See rights and permissions. Published by BMJ.

${ }^{1}$ Consultation-Liason Psychiatry, Brigham and Women's Hospital, Boston, Massachusetts, USA ${ }^{2}$ Department of Psychiatry, Harvard Medical School, Boston, Massachusetts, USA

${ }^{3}$ Biological Psychiatry Laboratory, McLean Hospital, Belmont, Massachusetts, USA ${ }^{4}$ Clinical Sciences/College of Pharmacy, Touro University California, Vallejo, California, USA ${ }^{5}$ Department of Medicine, Stanford University School of Medicine, Stanford, California, USA

${ }^{6}$ Iowa Board of Pharmacy, lowa Department of Public Health, Des Moines, lowa, USA

Correspondence to Dr Harrison Pope; hpope@mclean.harvard.edu

\section{ABSTRACT}

Objectives Hundreds of thousands, if not millions, of individuals worldwide engage in competitive body-building. Body-building often attracts derogatory characterisations such as as 'bizarre' or 'narcissistic,' or a 'freak show', seemingly implying that it is associated with pathology. Few studies have compared psychological features in competitive bodybuilders versus recreational strength trainers.

Methods Using logistic regression with adjustment for age and race, we compared 96 competitive bodybuilders ('competitors') with 888 recreational strength trainers ('recreationals'), assessed in a prior internet survey, regarding demographics; body image; use of anabolicandrogenic steroids (AAS), other appearance-enhancing and performance-enhancing drugs (APEDs), and classical drugs of abuse; history of psychiatric diagnoses; and history of childhood physical/sexual abuse.

Results Competitors reported a higher lifetime prevalence of AAS (61 (63.5\%) vs $356(10.1 \%), p<0.001)$ and other APED use than recreationals but showed very few significant differences on other survey measures. AAS-using competitors were more likely than AASusing recreationals to have disclosed their AAS use to a physician (31 (50.8\%) vs $107(30.0 \%), p=0.003)$. Both groups reported high levels of body image concerns but did not differ from one another (eg, 'preoccupation with appearance' caused significant reported distress or impairment in important areas of functioning for $18(18.8 \%)$ competitors vs $132(15.4 \%)$ recreationals, $\mathrm{p}=0.78)$. No significant differences were found on the prevalence of reported childhood physical abuse $(9(9.4 \%)$ vs $77(8.8 \%), p=0.80)$ or sexual abuse (4 (4.2\%) vs 39 $(4.5 \%), p=0.83)$. Competitors reported a lower lifetime prevalence of marijuana use than recreationals ( 38 (39.6\%) vs $514(57.9 \%), p=0.001)$.

Conclusion Aside from their APED use, competitive bodybuilders show few psychological differences from recreational strength trainers.

\section{INTRODUCTION}

The sport of body-building is becoming increasingly popular, both as a recreation and as a competitive sport. Competitive bodybuilders, unlike recreational bodybuilders, participate in formal organised competitions
What are the new findings?

- Some writers have characterised competitive body-building as 'bizarre' or 'narcissistic', but few empirical studies have assessed whether this sport is actually associated with elevated levels of psychopathology.

- Comparing 96 competitive bodybuilders with 888 recreational strength trainers, we found that competitors were much more likely to have used anabolic-androgenic steroids and other appearanceenhancing and performance-enhancing drugs.

- However, on a wide range of other measures, including demographic features; attitudes towards body image; use of alcohol, cigarettes and classical illicit drugs; history of any psychiatric diagnosis by a professional; and history of childhood physical or sexual abuse, competitors did not exhibit greater psychopathology than their recreational counterparts.

- Aside from their heavy use of potentially hazardous drugs, competitive bodybuilders do not appear to differ from recreational strength trainers on a wide range of characteristics.

with the goal of winning titles and/or money. As we have described previously, ${ }^{1}$ preparation for competition is a rigorous process which typically begins with a 'bulking phase' involving months of weightlifting and consuming a caloric surplus to gain as much muscle as possible. This is followed by a 'cutting phase', beginning 8-12 weeks prior to a competition, where competitors aggressively diet (ie, develop a caloric deficit) to lose as much body fat as possible while minimising muscle loss. To achieve an ideal hypermasculine figure, competitors often use anabolic-androgenic steroids (AAS) and other appearance-enhancing and performance-enhancing drugs (APEDs). Anabolic drugs, such as AAS, human growth hormone (HGH) and insulin, are particularly used in the bulking phase to facilitate muscle growth. During the cutting phase, competitors may also add diuretics, thyroid hormones such as tri-iodothyronine $\left(\mathrm{T}_{3}\right)$ and 
fat-burning substances such as clenbuterol or stimulants. Meanwhile, competitors must continually practice their posing routines, which include seven mandatory poses, as well as their own personal routines, in preparation for the contest day. ${ }^{2-4}$

Despite the rigours of preparation and the dangers of drug use, competitive body-building has grown increasingly popular. For example, one of many bodybuilding organisations, the International Federation of Body-building and Fitness, sponsors about 2500 body-building events annually around the world, some involving hundreds of competitors. ${ }^{5}$ Thus, although we are not aware of published estimates of the prevalence of competitive body-building, the number of competitors worldwide likely extends well into hundreds of thousands, if not millions.

Competitive body-building has long had an odd reputation. Although the sport requires much dedication and self-discipline, some writers have characterised it as bizarre-if not frankly pathological-an expression of 'comic book masculinity"; an activity 'on the fringe of organised sport"; an 'oddball sport shunned for its homoerotic imagery ${ }^{8}$; or even a 'freak show'. ${ }^{9}$ One review ${ }^{10}$ noted that bodybuilders have been depicted as 'experiencing feelings of inferiority, lacking masculinity, and displaying narcissistic and homosexual tendencies' (p147). A recent study recruited focus groups of boys and young adults to assess attitudes towards male body image. ${ }^{11}$ In the course of the study, all groups 'presented negative discourses of body-building', and the adult group represented bodybuilders as 'overly obsessed with their appearance' (p225). Are these various impressions justified?

Few studies have systematically assessed psychological features in competitive bodybuilders as compared with recreational strength trainers, and those that have done so have yielded mixed results. ${ }^{1}$ There is reasonable consensus that competitors use more AAS and other APEDs than their recreational counterparts, but no clear consensus with regard to other conditions. Specifically, some but not all studies have suggested that competitors show a higher prevalence of body image concerns than non-competitors-including especially 'muscle dysmorphia' - a disorder in which individuals develop a pathological concern that they are not sufficiently muscular. ${ }^{12}{ }^{13}$ Some studies have also suggested that competitors may be more prone than non-competitors to eating disorders or to to exercise dependence, but again the data are inconsistent. ${ }^{1}$ Thus, the question remains open as to whether competitors display an elevated prevalence of psychological abnormalities or whether popular belief overestimates their degree of psychopathology. To address this issue, we analysed responses from 984 competitive and recreational strength-training men, evaluated in the course of an internet survey.

\section{MATERIALS AND METHODS Study population}

The present study was based on the results of a 2009 internet survey, previously reported, of men who participated in strength training. ${ }^{14}$ Briefly, a 99 -item anonymous web-based survey was posted on 38 online discussion boards of fitness, body-building, AAS and weightlifting sites. The survey (available from the authors on request) asked about demographics; exercise patterns; use of AAS and of other APEDs (if any); use of alcohol, tobacco and classical drugs of abuse; attitudes and behaviours related to body image; diagnoses of psychiatric disorders that had been made by a health professional; and history of childhood physical and sexual abuse. The survey received 1519 complete and evaluable responses comprising 1277 men and 242 women.

For the present paper, we restricted analysis to the 1277 men. One of the initial survey questions asked respondents to classify themselves as 'recreational exercisers' (endorsed by 888 men), 'competitive bodybuilders' $(\mathrm{n}=96)$, 'competitive athletes' $(\mathrm{n}=139)$ and 'competitive weightlifters' $(n=154)$. Since we wished to analyse differences between competitive and non-competitive bodybuilders, we excluded the groups identifying

Table 1 Demographic features of competitive bodybuilders versus recreational strength trainers

\begin{tabular}{|c|c|c|c|c|}
\hline \multirow[b]{2}{*}{ Characteristics $^{*}$} & \multirow{2}{*}{$\begin{array}{l}\text { Competitive } \\
(\mathrm{n}=96)\end{array}$} & \multirow{2}{*}{$\begin{array}{l}\text { Recreational } \\
(\mathrm{n}=888)\end{array}$} & \multirow[b]{2}{*}{ Estimated difference (SE) } & \multirow[b]{2}{*}{$P$ value } \\
\hline & & & & \\
\hline \multirow[t]{2}{*}{ Age (years) $\dagger$} & $25.5(10.0)$ & $28.0(9.3)$ & $-2.5(1.0)$ & 0.015 \\
\hline & & & OR $(95 \% \mathrm{Cl})$ & \\
\hline Caucasian raceł & $80(83.3 \%)$ & $729(82.1 \%)$ & $1.1(0.6$ to 1.9$)$ & 0.76 \\
\hline Married & $33(34.4 \%)$ & $330(37.2 \%)$ & $1.8(1.0$ to 3.2$)$ & 0.050 \\
\hline Graduated 4-year college & $38(39.6 \%)$ & $409(46.1 \%)$ & $1.0(0.6$ to 1.6$)$ & 0.93 \\
\hline Obtained graduate/professional degree & $5(5.2 \%)$ & $57(6.4 \%)$ & $1.2(0.5$ to 3.2$)$ & 0.717 \\
\hline Annual income greater than US $\$ 100000$ & $15(15.6 \%)$ & $112(12.6 \%)$ & 2.0 (1.1 to 3.8$)$ & 0.033 \\
\hline One or more children & $18(18.7)$ & $214(24.1)$ & $1.2(0.6$ to 2.5$)$ & 0.55 \\
\hline
\end{tabular}

${ }^{*}$ Data are reported as mean (SD) or $\mathrm{n}(\%)$ as appropriate.

†Data missing on two recreationals.

‡Based on self-report. 
Table 2 Features of AAS use in competitive bodybuilders versus recreational strength trainers

\begin{tabular}{|c|c|c|c|c|}
\hline & Competitive & Recreational & & \\
\hline Characteristics* & $(n=96)$ & $(n=888)$ & OR $(95 \% \mathrm{Cl})$ & $P$ value \\
\hline Any AAS use in lifetime & $61(63.5 \%)$ & $356(10.1 \%)$ & $4.2(2.6$ to 7.0$)$ & $<0.001$ \\
\hline Age of first AAS use (years) & $23.1(7.2)$ & $25.1(7.8)$ & $-0.2(0.9)$ & 0.83 \\
\hline \multirow[t]{2}{*}{ Average duration of an AAS cycle (weeks) } & $10.1(5.5)$ & $9.6(5.2)$ & $0.6(0.7)$ & 0.40 \\
\hline & OR $(95 \% \mathrm{Cl})$ & & & \\
\hline \multicolumn{5}{|l|}{ Disclosed AAS use to } \\
\hline No one & $4(6.6 \%)$ & $32(9.0 \%)$ & $0.7(0.2$ to 2.1$)$ & 0.80 \\
\hline Trainer/coach & $9(14.8 \%)$ & $29(8.14 \%)$ & $1.9(0.8$ to 4.3$)$ & 0.14 \\
\hline Religious authority & $2(3.3 \%)$ & $2(0.6 \%)$ & $7.8(1.1$ to 57$)$ & 0.10 \\
\hline Physician & $31(50.8 \%)$ & $107(30.1 \%)$ & 2.4 (1.3 to 4.2$)$ & 0.003 \\
\hline Concerned about AAS side effects & $31(50.8 \%)$ & $204(57.3 \%)$ & 0.7 (0.4 to 1.2$)$ & 0.33 \\
\hline AAS dependence†‡ & $16(26.2 \%)$ & $79(22.2 \%)$ & $1.2(0.6$ to 2.3$)$ & 0.59 \\
\hline $\begin{array}{l}\text { Considers physicians knowledgeable about AAS/ } \\
\text { APEDs } \ddagger\end{array}$ & $5(8.3 \%)$ & $35(9.9 \%)$ & 0.8 (0.3 to 2.3$)$ & 0.73 \\
\hline $\begin{array}{l}\text { Considers pharmacists knowledgeable about } \\
\text { AAS/APEDs§ }\end{array}$ & $6(9.8 \%)$ & $50(14.3 \%)$ & $0.6(0.3$ to 1.6$)$ & 0.31 \\
\hline
\end{tabular}

*Data are reported as mean (SD) or $\mathrm{n}(\%)$ as appropriate.

†Endorsed at least three of the nine Diagnostic and Statistical Manual of Mental Disorders, Fourth Edition, criteria for dependence (adapted for AAS use).

fData missing on four recreationals and one competitor.

§Data missing on six recreationals.

IData missing on four recreationals.

AAS, anabolic-androgenic steroids; APED, appearance-enhancing and performance-enhancing drug.

themselves as competitive athletes and competitive weightlifters, respectively, since these two latter groups appeared more ambiguously defined and may have included some competitive bodybuilders mixed in with individuals in other competitive sports (eg, powerlifting, Olympic lifting and track and field). Thus, the final

Table 3 APED use of competitive bodybuilders versus recreational strength trainers

\begin{tabular}{|c|c|c|c|c|}
\hline \multirow[b]{2}{*}{ Characteristics* } & \multirow{2}{*}{$\begin{array}{l}\text { Competitive } \\
(n=96)\end{array}$} & \multirow{2}{*}{$\begin{array}{l}\text { Recreational } \\
(n=888)\end{array}$} & \multirow[b]{2}{*}{ OR $(95 \% \mathrm{Cl})$} & \multirow[b]{2}{*}{$P$ value } \\
\hline & & & & \\
\hline \multicolumn{5}{|l|}{ Lifetime reported use of } \\
\hline Insulin & $14(14.5 \%)$ & $21(2.36 \%)$ & 9.9 (4.7 to 21.1$)$ & $<0.001$ \\
\hline Human growth hormone & $12(12.5 \%)$ & $56(6.3 \%)$ & $3.2(1.6$ to 6.6$)$ & $<0.001$ \\
\hline Insulin-like growth factor-1 & $13(13.5 \%)$ & $27(3.04 \%)$ & 7.6 (3.6 to 16.1$)$ & $<0.001$ \\
\hline Clenbuterol & 37 (38.5\%) & $119(13.4 \%)$ & 5.4 (3.3 to 8.8$)$ & $<0.001$ \\
\hline Tri-iodothyronine $†$ & $26(27.1 \%)$ & 74 (8.33\%) & 6.4 (3.6 to 11.2$)$ & $<0.001$ \\
\hline Diuretics $\ddagger$ & $5(5.2 \%)$ & $12(1.35 \%)$ & 5.6 (1.8 to 16.8$)$ & 0.002 \\
\hline Spent more than $\$ 1000$ annually on drugs and supplements & $38(39.6 \%)$ & $192(21.6 \%)$ & 3.0 (1.8 to 4.8$)$ & $<0.001$ \\
\hline
\end{tabular}

${ }^{*}$ Data are reported as mean (SD) or $\mathrm{n}(\%)$ as appropriate.

†Data missing on four recreationals and one competitor.

$\ddagger$ Acetazolamide, furosemide, spironolactone and/or hydrochlorothiazide.

APED, appearance-enhancing and performance-enhancing drug. 
Table 4 Body image features of competitive bodybuilders versus recreational strength trainers

\begin{tabular}{|c|c|c|c|c|}
\hline \multirow[b]{2}{*}{ Characteristics* } & Competitive & Recreational & \multirow[b]{2}{*}{ OR $(95 \% \mathrm{Cl})$} & \multirow[b]{2}{*}{ P value } \\
\hline & $(n=96)$ & $(n=888)$ & & \\
\hline Preoccupied by an imagined defect or slight anomaly $\dagger$ & $39(40.6 \%)$ & $334(37.9 \%)$ & $0.9(0.6$ to 1.4$)$ & 0.69 \\
\hline $\begin{array}{l}\text { Distressed/impaired in some aspect of functioning due to } \\
\text { preoccupation with defect or anomaly } \ddagger\end{array}$ & $18(18.8 \%)$ & $132(15.3 \%)$ & $1.1(0.6$ to 1.4$)$ & 0.78 \\
\hline Perceiving self as overweight & $8(8.33 \%)$ & $237(26.7 \%)$ & $0.3(0.1$ to 0.6$)$ & 0.001 \\
\hline Perceiving self as underweight & $23(24 \%)$ & $139(15.7 \%)$ & 1.5 (0.9 to 2.5$)$ & 0.12 \\
\hline Perceiving weight as 'just about right' & $65(67.7 \%)$ & $506(57 \%)$ & 1.5 (1.0 to 2.5$)$ & 0.058 \\
\hline Trying to gain weight & $57(59.4 \%)$ & $437(49.2 \%)$ & $1.2(0.8$ to 1.9$)$ & 0.34 \\
\hline Trying to lose weight & $24(25 \%)$ & $266(30 \%)$ & $0.9(0.5$ to 1.5$)$ & 0.66 \\
\hline Trying to maintain weight & $15(15.6 \%)$ & $175(19.7 \%)$ & $0.9(0.5$ to 1.6$)$ & 0.68 \\
\hline
\end{tabular}

${ }^{*}$ Data are reported as $\mathrm{N}(\%)$.

†Data missing on seven recreationals.

$\ddagger$ Data missing on 23 recreationals.

comparison involved the 96 competitive bodybuilders (abbreviated further and in the tables as 'competitors') and the 888 recreational strength-training men (abbreviated as 'recreationals').

\section{Patient and public involvement}

Patients or the public were not involved in the design, conduct, reporting or dissemination plans of our research.

\section{Statistical analysis}

We first compared the competitive and recreational groups on age and race/ethnicity, with the significance of differences between groups assessed by a t-test and by Fisher's exact test, respectively. For comparisons between the two groups on all subsequent variables, we used logistic regression for binary outcome variables and linear regression for continuous outcome variables, with adjustments for age (modelled in quartiles as ordered categories of age less than 21, 21-25, 26-32 and 33 years or greater) and race (modelled as Caucasian vs all others). For most variables assessed, there were no missing data; variables with missing data are noted in the tables.

Given that we performed approximately 50 comparisons in this study, it was important to adjust significance levels to allow for multiple comparisons. Since many of the outcome variables were associated with one another (eg, AAS use and use of other APEDs, such as HGH), a Bonferroni correction would be overly conservative and would risk causing type II errors. Therefore, we judged that a 10 -fold reduction in the value of $\mathrm{p}$ required for

Table 5 Other substance use in competitive bodybuilders versus recreational strength trainers

\begin{tabular}{|c|c|c|c|c|}
\hline & Competitive & Recreational & & \\
\hline Characteristics* & $(n=96)$ & $(n=888)$ & OR $(95 \% \mathrm{Cl})$ & $P$ value \\
\hline \multicolumn{5}{|l|}{ Lifetime history of } \\
\hline Heavy alcohol use $†$ & $13(13.5 \%)$ & $183(20.6 \%)$ & 0.7 (0.4 to 1.3$)$ & 0.24 \\
\hline Cigarette smoking & $32(33.3 \%)$ & $375(42.2 \%)$ & $0.7(0.5$ to 1.1$)$ & 0.13 \\
\hline Marijuana use & 38 (39.6\%) & 514 (57.9\%) & 0.5 (0.3 to 0.7$)$ & 0.001 \\
\hline Cocaine use & $15(15.6 \%)$ & $215(24.2 \%)$ & $0.6(0.4$ to 1.1$)$ & 0.12 \\
\hline Crack cocaine use & $4(4.2 \%)$ & $56(6.0 \%)$ & 0.7 (0.3 to 2.1$)$ & 0.54 \\
\hline Inhalant use & $4(4.2 \%)$ & $60(6.8 \%)$ & $0.6(0.2$ to 1.8$)$ & 0.40 \\
\hline Hallucinogen use & $11(11.5 \%)$ & $151(17.0 \%)$ & 0.7 (0.3 to 1.3$)$ & 0.23 \\
\hline PCP use & $5(5.2 \%)$ & $50(5.6 \%)$ & $1.0(0.4$ to 2.5$)$ & 0.97 \\
\hline LSD use & $6(6.3 \%)$ & $122(13.7 \%)$ & $0.5(0.2$ to 1.1$)$ & 0.071 \\
\hline Heroin use & $7(7.3 \%)$ & 52 (5.9\%) & $1.4(0.6$ to 3.2$)$ & 0.45 \\
\hline Stimulant use & $17(17.7 \%)$ & $181(20.4 \%)$ & $0.9(0.5$ to 1.5$)$ & 0.57 \\
\hline Use of any illicit drug other than marijuana & $12(12.5 \%)$ & $145(16.3 \%)$ & $0.7(0.4$ to 1.4$)$ & 0.35 \\
\hline
\end{tabular}

${ }^{*}$ Data are reported as $\mathrm{n}(\%)$.

†Five or more drinks on the same occasion on five or more days within a 30-day period.

LSD, lysergic acid diethylamide; PCP, phencyclidine. 
Table 6 Psychiatric diagnoses in competitive bodybuilders versus recreational strength trainers

\begin{tabular}{|c|c|c|c|c|}
\hline \multirow[b]{2}{*}{ Characteristics $^{*}$} & Competitive & Recreational & \multirow[b]{2}{*}{ OR $(95 \% \mathrm{Cl})$} & \multirow[b]{2}{*}{$P$ value } \\
\hline & $(n=96)$ & $(n=888)$ & & \\
\hline \multicolumn{5}{|c|}{ Ever diagnosed by a doctor or health professional with } \\
\hline Depression & $6(6.3 \%)$ & $79(9.0 \%)$ & 0.7 (0.3 to 1.7$)$ & 0.43 \\
\hline Anxiety & $9(9.4 \%)$ & $70(7.9 \%)$ & 1.4 (0.6 to 2.9$)$ & 0.42 \\
\hline Obsessive compulsive disorder & 0 & $16(1.8 \%)$ & - & $0.11 \dagger$ \\
\hline Body dysmorphic disorder & $1(1.0 \%)$ & $4(0.5 \%)$ & $1.7(0.2$ to 16$)$ & $0.40 \dagger$ \\
\hline Substance Dependence & 0 & $12(1.4 \%)$ & - & $0.62 \dagger$ \\
\hline Attention deficit hyperactivity disorder & $5(5.2 \%)$ & $33(3.7 \%)$ & $1.6(0.6$ to 4.1$)$ & 0.38 \\
\hline Anorexia nervosa & $1(1.0 \%)$ & $3(0.3 \%)$ & 3.1 (0.3 to 30$)$ & 0.34 \\
\hline Bulimia nervosa & 0 & $3(0.3 \%)$ & - & $1.0+$ \\
\hline Schizophrenia & 0 & $2(0.3 \%)$ & - & $1.0 \dagger$ \\
\hline Any type of psychiatric diagnosis & $14(14.6 \%)$ & $143(16.1 \%)$ & 0.9 (0.5 to 1.6$)$ & 0.74 \\
\hline History of physical abuse $\ddagger$ & $9(9.4 \%)$ & $77(8.8 \%)$ & 1.1 (0.5 to 2.3$)$ & 0.80 \\
\hline History of sexual abuse§ & $4(4.2 \%)$ & $39(4.5 \%)$ & 1.1 (0.4 to 3.3$)$ & 0.83 \\
\hline
\end{tabular}

*Data are reported as $\mathrm{n}(\%)$.

†Computed by Fisher's exact test because of the presence of 0 cell.

‡Data missing on 13 recreationals.

$\S$ Data missing on 13 recreationals.

significance (ie, a requirement of $\mathrm{p}<0.005$ or better) represented a reasonable correction for multiple comparisons. Although we provide some mention of findings that fell into the range of $0.005<\mathrm{p}<0.05$, such findings should be regarded cautiously as possible chance associations.

\section{RESULTS}

\section{Demographic features}

The 96 competitors were slightly younger than the recreationals, but the two groups showed a similar prevalence of Caucasian race (table 1). In analyses adjusting for age and race, we found no significant differences between the groups on marital status, annual income of greater than $\$ 100000$, having at least one child or level of higher education. None of the competitors identified themselves as gay or bisexual, as compared with about $4.4 \%$ of recreationals, but the nominal $p$ value of 0.027 on this comparison failed to reach our adjusted alpha of 0.005 .

\section{AAS and APED use}

As expected, the proportion of competitors reporting any lifetime AAS use was markedly and significantly higher than in the recreationals (table 2). Comparing those men who had used AAS within each group, we found no significant differences in age of onset of AAS use, in various measures of usage patterns, or in the prevalence of an apparent history of AAS dependence. Notably, however, AAS-using competitors were significantly more likely than AAS-using recreationals to have disclosed their AAS use to a physician. This difference is particularly notable in light of the fact that fewer than $10 \%$ of the AAS-using competitors responded that "physicians are knowledgeable about anabolic steroids and performance-enhancing medications/supplements'.

Also as expected, competitors were significantly more likely than recreationals to report use of other APEDs, including clenbuterol, insulin, HGH, insulin-like growth factor- $1, \mathrm{~T}_{3}$ and diuretics (table 3). Among the men in both groups who did not report use of AAS, reported use of these other APEDs was minimal: of the 35 non-AASusing competitors, only $2(5.6 \%)$ had used clenbuterol; $1(2.9 \%)$ had used $\mathrm{T}_{3}$; and none reported use of any of the other APEDs listed in the previous sentence. Among the 532 non-AAS-using recreationals, 11 (2.1\%) reported using clenbuterol; $4(1.3 \%)$ reported using $\mathrm{T}_{3}$; and fewer than $1 \%$ reported use of any other category of APED.

\section{Body image}

Turning to questions regarding body image, about $40 \%$ of respondents in both groups reported that they were 'preoccupied with an imagined defect or slight physical anomaly in your appearance', and about $20 \%$ of the men in each group responded positively to the question 'is there a preoccupation with your appearance causing significant distress or impairment in social, occupational, or other important areas of functioning?' (table 4). However, there were no significant differences between groups on either of these measures. The groups also did not differ on most measures of self-perceived body image, except that competitors were significantly less likely to perceive themselves as overweight.

\section{Psychiatric and substance-use measures}

Competitors were significantly less likely to report having used marijuana than recreationals and also were 
generally less likely to have used other drugs, including heavy alcohol use and cigarette smoking, although the latter comparisons failed to reach significance and often involved small numbers (table 5).

Looking at psychiatric diagnoses made by a doctor or another health professional, we found that both groups reported a low prevalence of having been diagnosed with any individual psychiatric disorder or with psychiatric disorders as a whole (table 6), and no significant differences emerged on any of these comparisons. Both groups also reported low rates of childhood physical or sexual abuse and did not differ from each another on these variables as well.

\section{DISCUSSION}

Competitive body-building - a sport requiring rigorous preparation and self-discipline-is practised by many hundreds of thousands, if not millions, of individuals worldwide. However, the sport has a peculiar reputation; in both scientific publications and in popular belief, competitive bodybuilders are sometimes portrayed as prone to psychopathology, or even as participating in a freak show. Few studies, however, have asked whether these impressions are scientifically supported.

To address this question, we compared 96 male competitive bodybuilders and 888 recreational strength-training men assessed in an internet survey. We found that the competitors reported a much higher lifetime prevalence of use of AAS and other APEDs, as had been expected. However, on a wide range of other measures, including demographic features, attitudes towards body image, use of alcohol and cigarettes, use of illicit drugs, history of any psychiatric diagnosis by a professional, and history of childhood physical or sexual abuse, we found little evidence that competitors exhibited greater pathology than their recreational counterparts. Competitors also showed no significant differences from recreational trainers on level of education, marital status, having children or income. None of the competitors reported a homosexual or bisexual orientation, as compared with $4.4 \%$ of the recreationals.

Respondents in both the competitive and recreational groups reported high levels of concern with body image, with about $40 \%$ responding that they were "preoccupied' with an imagined defect or slight physical anomaly, and $20 \%$ responding that this caused distress or impairment in some areas of functioning. However, we found no significant differences between the competitive and recreational groups on these measures. The groups also showed no significant differences on attitudes towards body weight, save for the fact that competitors were significantly less likely to perceive themselves as overweight. Thus, although body image and body weight appear to represent widespread concerns among strength-training men, these concerns are by no means confined to competitors.

Indeed, setting aside their high levels of AAS and other APED use, one might even argue that the competitors were slightly more 'responsible' or health-conscious than recreationals in certain ways, in that they reported a markedly lower lifetime prevalence of marijuana use and were less likely to consider themselves as overweight, as just mentioned. Also, the AAS-using competitors were significantly more likely than AAS-using non-competitors to have involved their doctors by disclosing their AAS use. However, these impressions might conceivably apply only to certain subcategories of competitors rather than to competitors as a whole, as discussed in the Limitations section.

In any case, our findings here seem generally congruent with the findings of several other investigators who have failed to find elevated rates of psychopathology in comparisons between competitive and non-competitive bodybuilders. ${ }^{15-17}$ For example, although Goldfield and colleagues $^{16}$ found that competitive bodybuilders were significantly more likely to have met Diagnostic and Statistical Manual of Mental Disorders, Fourth Edition, criteria $^{18}$ for bulimia nervosa than recreational bodybuilders, these authors found no significant differences between these groups on a range of other psychological measures from the Eating Disorders Inventory. ${ }^{19}$ Similarly, Pickett and colleagues ${ }^{17}$ found no support for the assumption that muscle dysmorphia was more prevalent in a group of 40 competitive bodybuilders as compared with 40 noncompetitive bodybuilders or 40 physically active men who did not lift weights. Indeed, these investigators suggested that competitive bodybuilders exhibited a better overall body image then either of the other groups in the study.

\section{Limitations}

Several limitations should be considered when assessing our findings. First, the internet survey that we used was not specifically designed for comparing competitive with non-competitive bodybuilders on measures of psychopathology, and thus we were limited by the questions that had been chosen when the survey instrument was originally created. For example, although the instrument asked extensively about substance use, it contained fewer questions about body image and eating disorders, no questions that specifically addressed exercise addiction. Thus, possible differences between competitive and non-competitive bodybuilders on these indices might have been missed for lack of detailed inquiry. Second, although the study sample was large, there remains a possibility of a type II error on some of the questions due to inadequate power. Third, the survey questions were not validated by testing them on a live sample of actual participants prior to conducting the survey. Fourth, there is a risk of selection bias, in that individuals who chose to respond to the survey may not have been representative of the overall source population of strength-training men. However, factors such as selection bias or the use of questions lacking formal validation are mitigated by the fact that we were comparing two subgroups within the larger overall group of respondents. Therefore, differences between the subgroups would still likely be valid unless 
there were differential selection bias or interpretation of questions between the subgroups. For example, suppose that bodybuilders with body image preoccupations were much more motivated to respond to the survey than those without such preoccupations. Even in this case, the comparison of groups on body image questions would remain valid, barring the unlikely possibility that competitive bodybuilders with body image preoccupations were motivated to respond while recreational bodybuilders with equally prominent body image preoccupations were not motivated to respond.

Finally, the study was limited by the fact that the survey instrument category of competitive bodybuilder, which was used for our study here, failed to distinguish among the several different classes of competitive bodybuilders, such as 'men's physique', 'classic physique', '212' and 'open' categories. ${ }^{20}$ For example, the open category has no weight or size limitation as a judgement criterion, so that in this category, the largest bodybuilder wins (assuming that his level of symmetry and definition is the same as his rivals). By contrast, in the 212 category, competitors must be less than or equal to $212 \mathrm{lb}$ in weight and $5 \mathrm{ft} 5$ inches in height. In the two 'physique' categories, sheer size is less important (eg, in men's physique, competitors wear knee-length shorts, and legs are not judged), and thus, these categories might arguably represent almost a different sport, likely associated with lower levels of drug use and less sacrifice of other aspects of lifestyle than all-out open or even 212 competitors. In short, the findings in this paper are likely derived from a heterogeneous group of competitive bodybuilders and might not hold for a particular subgroup. Future studies should take care to operationalise their definitions of competitive body-building in order to address this issue.

\section{CONCLUSION}

In summary, the findings of this survey tentatively suggest that, despite its occasional reputation as 'bizarre', 'narcissistic' or a freak show, competitive body-building does not appear to be associated with significantly more psychopathology than non-competitive recreational strength training. The exception to this finding is that competitive bodybuilders do use significantly more AAS and other potentially dangerous APEDs than their non-competitive counterparts, although it must be acknowledged that competitive body-building is hardly the only sport in which athletes are willing to take substantial risks in order to win.

Contributors Contributors EJI and MJB designed and conducted the original internet study that provided data for the present publication. They also assisted in data analysis in the present study and in revising the work for important intellectual content. IS, HP and GK designed the present study, performed data analysis and interpretation, and drafted the report of the work. All authors provided final approval for the manuscript. HP is the corresponding author and guarantor of the results.

Funding This study was conducted without external or internal funding. Competing interests None declared.

\section{Patient consent for publication Not required.}

Ethics approval This study was determined to be exempted by the Touro University Institutional Review Board because it did not involve 'interaction or intervention with individuals', and the information obtained was not 'individually identifiable' or 'readily ascertained by the investigator are associated with the information'.

Provenance and peer review Not commissioned; externally peer reviewed.

Data availability statement Data will be made available upon reasonable request.

Open access This is an open access article distributed in accordance with the Creative Commons Attribution Non Commercial (CC BY-NC 4.0) license, which permits others to distribute, remix, adapt, build upon this work non-commercially, and license their derivative works on different terms, provided the original work is properly cited, appropriate credit is given, any changes made indicated, and the use is non-commercial. See: http://creativecommons.org/licenses/by-nc/4.0/.

\section{ORCID iDs}

lan Steele http://orcid.org/0000-0003-1375-8630

Harrison Pope http://orcid.org/0000-0003-1298-6439

Eric J Ip http://orcid.org/0000-0003-3997-995X

Mitchell J Barnett http://orcid.org/0000-0002-9645-9865

Gen Kanayama http://orcid.org/0000-0002-1587-6051

\section{REFERENCES}

1 Steele IH, Pope HG, Kanayama G. Competitive bodybuilding: fitness, pathology, or both? Harv Rev Psychiatry 2019;27:233-40.

2 Fussell S. Muscle: Confessions of an unlikely bodybuilder. New York: Poseidon Press, 1991.

3 Lambert CP, Frank LL, Evans WJ. Macronutrient considerations for the sport of bodybuilding. Sports Med 2004;34:317-27.

4 Schwarzenegger A, Dobbins B. The new encyclopedia of modern bodybuilding. New York: Simon \& Schuster, 1998.

5 Richardson N. Introduction to Part I: What is the "practice" of bodybuilding? In: Locks A, Richardson R, eds. Critical readings in bodybuilding. New York: Routledge, 2012.

6 Klein AM. Comic book masculinity. Sport in Society 2007;10:1073-119.

7 Holm S. Changes to bodily appearance: the aesthetics of deliberate intervention. Med Humanit 2000;26:43-8.

8 Boyle E. Marketing muscular masculinity in Arnold: the education of a bodybuilder. J Gend Stud 2010;19:153-66.

9 Lindsay C. Bodybuilding: a postmodern freak show. In: Thompson R, ed. Freakery: cultural spectacles of the extraordinary body. New York: New York University press, 1996: 356-67.

10 Weigers Y. The social construction of a masculine identity. J Popul Cult 1998;32:147-61.

11 Grogan S, Richards H. Body image: focus groups with boys and men. Men and Masculin 2002;4:219-32.

12 Pope HG, Gruber AJ, Choi P, et al. Muscle dysmorphia. An underrecognized form of body dysmorphic disorder. Psychosomatics 1997;38:548-57.

13 Suffolk MT, Dovey TM, Goodwin H, et al. Muscle dysmorphia: methodological issues, implications for research. Eat Disord 2013;21:437-57.

14 Ip EJ, Barnett MJ, Tenerowicz MJ, et al. The anabolic 500 survey: characteristics of male users versus nonusers of anabolicandrogenic steroids for strength training. Pharmacotherapy 2011;31:757-66.

15 Ahmadi S, Jabari N, Gale M, et al. Body dissatisfaction and mental health of competitive and recreational male bodybuilders. World Appl Sci Journal 2013;21:58-62.

16 Goldfield GS, Blouin AG, Woodside DB. Body image, binge eating, and Bulimia nervosa in male bodybuilders. Can J Psychiatry 2006;51:160-8

17 Pickett TC, Lewis RJ, Cash TF. Men, muscles, and body image: comparisons of competitive bodybuilders, weight trainers, and athletically active controls. Br J Sports Med 2005;39:217-22.

18 American Psychiatric Association. Diagnostic and statistical manual of mental disorders, fourth edition (DSM-IV. Washington, DC: American Psychiatric Association, 1994.

19 Garner DM, Olmstead MP, Polivy J. Development and validation of a multidimensional eating disorder inventory for anorexia nervosa and Bulimia. Int J Eat Disord 1983;2:15-34.

20 International Federation of bodybuilding and fitness. Available: https://ifbb.com/rules-2 [Accessed 27 Feb 2020]. 